\title{
Timing of blood extraction in epidemiologic and proteomic studies: results and proposals from the PANKRAS II Study
}

\author{
Miquel Porta $\cdot$ José Pumarega $\cdot$ Olga Ferrer-Armengou $\cdot$ Tomàs López $\cdot$ \\ Joan Alguacil · Núria Malats · Esteve Fernàndez $\cdot$ for the PANKRAS II Study Group
}

Published online: 10 October 2007

(C) Springer Science+Business Media B.V. 2007

\section{Erratum to: Eur J Epidemiol 22:577-588 (2007)}

\section{DOI: $10.1007 / \mathrm{s} 10654-007-9149-7$}

An incorrect version of the Acknowledgements was published for this article.

The Acknowledgements should read as follows:

Acknowledgements This work was supported by research grants from Generalitat de Catalunya (CIRIT SGR 0241, SGR 0078); 'Red temática de investigación cooperativa de centros en Cáncer' (C03/10),
'Red temática de investigación cooperativa de centros en Epidemiología y salud pública' (C03/09); CIBER de Epidemiología y Salud Pública (CIBERESP), Instituto de Salud Carlos III and the US National Cancer Institute, project "Use of the Serum Proteome on the Early Diagnosis of Malignant Biliary-Pancreatic Disease. Follow-up of the PANKRAS II Sub-cohort with Benign Pathology" (04-CN272). The authors gratefully acknowledge scientific advice provided by Elisa Puigdomènech, Marta Crous-Bou, Ángel Vicente, Luisa Guarner, Francisco X. Real, Juli Rifà, Alfredo Carrato and Josep M. Corominas, as well as technical assistance from David J. MacFarlane, Isabel Egea and Silvia Geeraerd.

The online version of the original article can be found under doi: 10.1007/s10654-007-9149-7.

M. Porta $(\bowtie) \cdot$ J. Pumarega - O. Ferrer-Armengou - T. López ·

J. Alguacil - N. Malats · for the PANKRAS II Study Group

Clinical \& Molecular Epidemiology of Cancer Unit, Institut

Municipal d'Investigació Mèdica, Universitat Autònoma de

Barcelona, Carrer del Dr. Aiguader 88, 08003 Barcelona,

Catalonia, Spain

e-mail: mporta@imim.es

M. Porta

School of Medicine, Universitat Autònoma de Barcelona,

Barcelona, Spain

M. Porta · J. Pumarega $\cdot$ T. López · J. Alguacil

CIBER en Epidemiología y Salud Pública (CIBERESP),

Barcelona, Spain

J. Alguacil

Department of Environmental Biology \& Public Health,

University of Huelva, Huelva, Spain

E. Fernàndez

Institut Català d'Oncologia, Barcelona, Spain 